\title{
FORMULATION AND IN VITRO EVALUATION OF AMLODIPINE GASTRORETENTIVE FLOATING TABLETS USING A COMBINATION OF HYDROPHILIC AND HYDROPHOBIC POLYMERS
}

\author{
ANAS T. ALHAMDANY*, ALI KHIDHER ABBAS
}

Department of Pharmaceutics, College of Pharmacy, Mustansiriyah University, Baghdad, Iraq Email: Pharm.anas.alhamdany@uomustansiriyah.edu.iq

Received: 23 Jul 2018, Revised and Accepted: 04 Sep 2018

\section{ABSTRACT}

Objective: The aim of this study was to formulate a developed floating tablet of amlodipine using different concentrations and types of hydrophilic and hydrophobic polymers to be conserved in the stomach for modulating solubility and bioavailability, diminishes drug waste and decline side effects.

Methods: Through this study, eleven innovative formulations of amlodipine floating tablets were prepared [mixture of amlodipine, sodium bicarbonate $\left(\mathrm{NaHCO}_{3}\right.$ ), hydroxypropyl methylcellulose (HPMC) E50, HPMC K100M, ethylcellulose (EC) 5 mp. a. s.] by direct compression method. The pre-compressed mixtures were then evaluated for numerous parameters such as angle of repose, bulk density, tapped density, Carr's compressibility index and Hausner's ratio. After compression, tablets were subjected to several tests like; floating behavior of tablets, tablet thickness, hardness test, friability test, weight variation, in vitro dissolution test. In addition, the optimum formulation was evaluated for Fourier transform-infrared (FT-IR) and differential scanning calorimetry (DSC) tests.

Results: From in vitro dissolution tests and kinetic assessments; F8 was selected as an optimum formula, depending on the $\mathrm{R}^{2}$ value of zero order kinetics (0.9915) and (n) value of Korsmeyer-Peppas (0.9635) which indicate purely relaxation zero order kinetic with good delaying in drug release that was reached to $14 \mathrm{~h}$.

Conclusion: It can be concluded that the developed formulation of a certain combination of low viscosity grades of HPMC and EC was considered an efficient floating tablet.

Keywords: Floating tablet, Gastroretentive, Amlodipine, EC 5 mp. a. s., HPMC E50, HPMC K100M

(C) 2018 The Authors. Published by Innovare Academic Sciences Pvt Ltd. This is an open access article under the CC BY license (http://creativecommons.org/licenses/by/4.0/) DOI: http://dx.doi.org/10.22159/ijap.2018v10i6.28687

\section{INTRODUCTION}

Over $90 \%$ of the formulations manufactured today are ingested orally. This show that this class of formulation is the most popular worldwide and major attention of the researcher is towards this direction [1]. Furthermore, oral delivery of drugs is the utmost chosen route of drug delivery due to the ease of administration; low cost of therapy, patient compliance, and flexibility in formulation [2]. In addition, this drug delivery system gives place for a therapeutic amount of drug to the desired site in the body to attain promptly and then preserve desired drug concentration [3].

Gastric emptying is an intricate process with high inconstant and alteration in vivo execution of drug delivery system [4]. Prolonged gastric retention enhances bioavailability, minimize drug waste, and ameliorate solubility of drugs with less solubility in an elevated $\mathrm{pH}$ environment [5]. Numerous trials have been made to conserve the dosage form in the stomach as a method of increment in the retention time. These trials involve presenting floating dosage forms (gas-generating systems and swelling or expanding systems), mucoadhesive systems, high-density systems, modified shape systems, gastric-emptying delaying devices and co-administration of gastric-emptying delaying drugs. Between these, the furthermost ordinarily used system is the floating dosage forms $[6,7]$.

The idea of floating tablets is primarily constructed on the drug delivery system of matrix type, so the drug exists embedded in the matrix which after approaching in contact with the gastric fluid swells up, and the slow erosion of the drug without disintegration of the tablet takes place [8]. In these sorts of drug delivery system, the gel-forming hydrocolloid and the drug are mixed carefully. Afterward oral administration, this dosage form upon impinging with gastric fluids it swells and achieves a bulk density of $<1$. The entrapped air inside the swollen matrix pickup flotation to the dosage form. Therefore, the designed gel-like structure is swollen and turns as a barrage and permits the release of the drug in a sustained form over the gelatinous mass. Drug release from hydrophilic matrix tablets is taking control by the creation of a hydrated viscous layer around the tablet which turns as a barrier to drug release by opposing penetration of water into tablet and movement of dissolved solutes out of the matrix tablets [9-11].

Amlodipine (AD) can be classified into the group of calcium channel blockers. Thus, it is frequently used to treat different heart diseases like angina and hypertension [12, 13]. Moreover, it has an ultimate solubility in acidic pH [14]. Based on this, an attempt was made through this investigation to formulate floating tablet of amlodipine besylate using different hydrophilic and hydrophobic polymers and their combinations; thus, conserve in the stomach to modulate solubility, bioavailability, diminishes drug waste and decline side effects such as gastric irritation and nausea.

\section{MATERIALS AND METHODS}

\section{Materials}

Amlodipine Besylate (Samara drug industry, Iraq), Avicel (Samara drug industry, Iraq), Talc (Samara drug industry, Iraq), Magnesium Stearate (Samara drug industry, Iraq), Hydroxypropyl methylcellulose (HPMC) E50 and HPMC K100 (Aladdin, China), Ethylcellulose (EC) $5 \mathrm{mp}$. a. s. (Aladdin, China), Sodium bicarbonate $\left(\mathrm{NaHCO}_{3}\right)$ (Samara drug industry, Iraq).

\section{Method}

\section{Preparation of floating amlodipine tablets}

The preparation of amlodipine floating tablets was done by direct compression method according to formulas given in (table 1). Floating tablets contained a mixture of amlodipine, sodium bicarbonate (as a generating agent of gas). Hydroxypropyl methylcellulose (HPMC) E50, HPMC K100M, ethylcellulose (EC) $5 \mathrm{mp}$. a. s act as rate controlling polymers. Altogether ingredients were precisely weighed then passed over sieve no.70. After sieving these ingredients were mixed uniformly for $10 \mathrm{~min}$. The powder blend was then mixed with the required 
amount of magnesium stearate and talc powders. After this addition, the mixture was further mixed for two minutes. The mixture result is compressed into tablets by a single punch tablet machine (Riva MIIUK) using $8 \mathrm{~mm}$ set of punch and die.

Table 1: Formulation of amlodipine floating tablets

\begin{tabular}{|c|c|c|c|c|c|c|c|c|c|c|c|}
\hline Formulas ingredients (mg) & F1 & F2 & F3 & F4 & F5 & F6 & F7 & F8 & F9 & F10 & F11 \\
\hline Amlodipine & 5 & 5 & 5 & 5 & 5 & 5 & 5 & 5 & 5 & 5 & 5 \\
\hline HPMC E50 & 50 & 60 & 70 & 80 & 90 & 80 & 80 & 80 & 80 & 80 & - \\
\hline HPMC K100M & - & - & - & - & - & - & - & - & - & - & 80 \\
\hline EC 5 mp. a.s & 5 & 5 & 5 & 5 & 5 & 10 & 20 & 30 & 40 & 30 & 30 \\
\hline Avicel & 133.5 & 123.5 & 113.5 & 103.5 & 93.5 & 98.5 & 88.5 & 78.5 & 68.5 & 73.5 & 78.5 \\
\hline $\mathrm{NaHCO}_{3}$ & 5 & 5 & 5 & 5 & 5 & 5 & 5 & 5 & 5 & 10 & 5 \\
\hline Mg Stearate & 1 & 1 & 1 & 1 & 1 & 1 & 1 & 1 & 1 & 1 & 1 \\
\hline Talc & 0.5 & 0.5 & 0.5 & 0.5 & 0.5 & 0.5 & 0.5 & 0.5 & 0.5 & 0.5 & 0.5 \\
\hline Total amount & 200 & 200 & 200 & 200 & 200 & 200 & 200 & 200 & 200 & 200 & 200 \\
\hline
\end{tabular}

\section{Characterization of floating amlodipine tablets}

\section{Pre-compression parameters}

The flow properties of powders before compression were qualified in terms of different tests that are according to US Pharmacopeia standards.

\section{Angle of repose}

The angle of repose utilized as indirect methods of determining powder flow ability due to their connection with interparticle cohesion. A static pile will slide when the inclination angle is vast enough to conquer frictional forces and stopover when gravitational forces balance the forces. The sides of the pile will produce an angle with horizontal which is termed as the angle of repose [15].

$$
\operatorname{Tan} \theta=\frac{\mathrm{h}}{\mathrm{r}}
$$

Where $h$ is the height of pile and $r$ is the radius of the pile.

\section{Bulk density}

Bulk density $(\mathrm{Pb})$ of floating tablets can be expressed in grams per cc $(\mathrm{g} / \mathrm{cc})$, and it was defined as the mass " $\mathrm{M}$ " of the powder picking a known volume ' $\mathrm{V}_{0}$ ' according to the relevance [16].

$$
\text { Bulk density }(\mathrm{Pb})=\frac{\text { Mass }(\mathrm{M})}{\text { Bulk volume }\left(\mathrm{V}_{0}\right)}
$$

It leans on particle size, shape, the tendency of the particle to adhere.

\section{Tapped density}

A weighed quantity of powder was introduced into a graduated cylinder and was tapped from a height of $2 \mathrm{~cm}$ for a fixed number of taps (100). It is the proportion of the weight of the sample to tapped volume [17].

$$
\text { Tapped density }=\frac{\text { Mass (M) }}{\text { Tapped volume (Vt) }}
$$

\section{Carr's compressibility index}

Carr's compressibility index constructed on the obvious bulk density and the tapped density, the percentage compressibility was determined as the following formula [18].

$$
\% \text { Compressibility }=\frac{\text { Tapped density-bulk density }}{\text { Tapped density }} \times 100
$$

\section{Hausner ratio}

Hausner's ratio can be determined as the ratio of tapped density to the bulk density of the powders and as the resulting equation [19].

$$
\text { Hausner's ratio }=\frac{\text { Tapped Density }}{\text { Bulk Density }}
$$

\section{Post-compression parameters}

\section{Content uniformity}

Assessment of drug content, 10 tablets were haphazardly selected and powdered. A measured amount of powder equivalent to the mass of one tablet $(200 \mathrm{mg}$ ) was precisely weighed and transferred into a volumetric flask and dissolved in $100 \mathrm{ml}$ of $0.1 \mathrm{~N} \mathrm{HCl}$. The flask was shaken until complete dissolving, and the solution was filtered. 1 $\mathrm{ml}$ of the above solution was diluted suitably with $0.1 \mathrm{~N} \mathrm{HCl}$. The absorbance of the resulting solution was measured at $366 \mathrm{~nm}$ using UV-visible spectrophotometer (Shimadzu 1650 pc-Japan) [20].

\section{Floating behavior of tablets}

These studies can be applicated by taking tablets $(n=3)$ and place in $1000 \mathrm{ml}$ of $0.01 \mathrm{~N} \mathrm{HCl}$ in USP type II dissolution apparatus (CopleyUSA) $\left(37 \pm 0.5^{\circ} \mathrm{C}, 50 \mathrm{rpm}\right)$. The time desired for tablets to be a float at the topmost of the medium was considered as floating lag time. The interval of time the tablet continuously keep on the surface was considered as the total floating time [21].

\section{Tablet thickness}

The thickness of the tablet was set using a vernier caliper (CopleyUK). Twenty floated tablets were used from each formula, and the average values were decided.

\section{Hardness test}

The hardness test was implemented in which 10 tablets from each formula were examined haphazardly, and the average reading $\pm S D$ was recorded as $\mathrm{kg} / \mathrm{cm}^{2}$ [22].

\section{Friability test}

The friability test was achieved by placing 20 pre-weighed tablets in the friabilator (Vanguard-USA) which was then run for one hundred revolutions; the tablets were then dusted and reweighed. Tablets that lose a maximum of not more than $1 \%$ of their weight are generally considered acceptable [23]. Percentage friability was calculated from the following equation:

$$
\% \text { Friability }=\frac{\left(\mathrm{W}_{0}\right)-(\mathrm{W})}{\left(\mathrm{W}_{0}\right)} \times 100
$$

$\mathrm{W}_{0}=$ weight of tablets before the test

$\mathrm{W}=$ weight of tablets after the test

\section{Weight variation}

This test was achieved by weighing 20 floating tablets separately and the average weight calculated. The demands are encountered if the weights of not more than 2 of the floating tablets differ from the average weight by more than the percentage recorded in the USP and no tablet varies in weight by more than double that percentage [24].

\section{In vitro dissolution studies}

The release of amlodipine from floating tablets was executed by USP Dissolution Test Apparatus Type-II (Paddle method; Copley-USA). The temperature of the dissolution medium $(0.1 \mathrm{~N} \mathrm{HCl}, 900 \mathrm{ml})$ was maintained at $37 \pm 1{ }^{\circ} \mathrm{C}$ with a stirring rate of $50 \mathrm{rpm}$. The floating tablets were dropped inside the dissolution apparatus vessels. A 5 $\mathrm{ml}$ sample of the solution was withdrawn hourly, and the same amount of samples were replaced with fresh dissolution medium. 
The obtained samples were filtered and analyzed in a triplicate using UV-visible spectrophotometer at $366 \mathrm{~nm}$ and the \% drug release was calculated using an equation obtained from a standard calibration curve [25].

\section{Kinetic assessment of dissolution data}

The dissolution rate data obtained were evaluated for compatibility with the kinetics of zero order, first-order, Higuchi, and KorsmeyerPeppas and verdict the $\mathrm{R}^{2}$ values of the dissolution profile incongruent to each model. The time required for $80 \%$ ( $\left.\mathrm{T}_{80 \%}\right) \mathrm{drug}$ release was calculated according to the best fit model with the highest determination $\mathrm{R}^{2}$ [26].

\section{Drug-excipients interaction study and identification}

\section{Fourier transform infrared spectroscopy (FT-IR)}

Compatibility studies were implemented to distinguish the conceivable interactions between Amlodipine and polymers used in the formulation. Physical mixtures of drug and polymers were all set to study the compatibility. These compatibility studies were achieved utilizing FT-IR spectrophotometer (SPECTROLAB MB3000, UK). The IR spectra's scanning range were recorded in between $450-4000 \mathrm{~cm}^{-1}$ [27].

\section{Differential scanning calorimetry (DSC)}

The possibility of drug-excipient interaction was further investigated by differential scanning calorimetry. DSC curve for each of pure powders of amlodipine, hydroxypropyl methylcellulose (HPMC) E50, ethylcellulose (EC) $5 \mathrm{mp}$. a. s., in addition to the physical mixture of the optimum formula of amlodipine in the presence of polymers (Precompression) and compressed tablet (post compression) analysis, was implemented using DSC instrument (DSC-60, Shimadzu-Japan). The samples were accurately weighed and heated in a sealed aluminum pan at a rate of 10 ${ }^{\circ} \mathrm{C} / \mathrm{min}$. within a 10 and $250^{\circ} \mathrm{C}$ temperature range under a nitrogen flow of $40 \mathrm{ml} / \mathrm{min}$. Alumina was utilized as a reference [15].

\section{RESULTS AND DISCUSSION}

\section{Characterization of floating amlodipine tablets}

\section{Pre-compression parameters}

Pre-compression parameters play a vital role in improving the flow properties of pharmaceuticals, particularly in tablet formulation. These contain an angle of repose, bulk density, tapped density, Carr's index, and Hausner ratio.

\section{Angle of repose}

Flow properties of the powder, the resistance of particle to particle movement could be arbitrated by using the angle of repose. This mensuration gives a qualitative and quantitative estimation of internal cohesive and frictional force under low levels of the external load as might be utilized in mixing and tablet compression [18]. Values for the angle of repose were showed in (table 2) and found to be in the range of $21.15^{\circ} \pm 0.25$ to $31.23^{\circ} \pm 0.22$ indicating excellent flow properties.

Tablet 2: Pre-compression parameters of the prepared amlodipine tablets

\begin{tabular}{|c|c|c|c|c|c|}
\hline Formula code & Angle of repose & Bulk density (g/cc) & Tapped density (g/cc) & Compressibility index (\%) & Hausner's ratio \\
\hline F1 & $28.67 \pm 0.34$ & $0.431 \pm 0.06$ & $0.591 \pm 0.09$ & $22.1 \pm 0.05$ & $0.065 \pm 0.11$ \\
\hline $\mathrm{F} 2$ & $21.30 \pm 0.27$ & $0.583 \pm 0.11$ & $0.496 \pm 0.12$ & $24.05 \pm 0.09$ & $1.81 \pm 0.05$ \\
\hline F3 & $28.15 \pm 0.39$ & $0.561 \pm 0.01$ & $0.632 \pm 0.08$ & $21.78 \pm 0.12$ & $0.141 \pm 0.03$ \\
\hline $\mathrm{F} 4$ & $26.19 \pm 0.31$ & $0.571 \pm 0.02$ & $0.519 \pm 0.05$ & $21.07 \pm 0.06$ & $1.15 \pm 0.09$ \\
\hline F5 & $24.34 \pm 0.28$ & $0.521 \pm 0.07$ & $0.632 \pm 0.14$ & $17.32 \pm 0.14$ & $0.146 \pm 0.03$ \\
\hline F6 & $31.23 \pm 0.22$ & $0.437 \pm 0.04$ & $0.623 \pm 0.11$ & $28.78 \pm 0.03$ & $0.121 \pm 0.07$ \\
\hline F7 & $21.15 \pm 0.25$ & $0.541 \pm 0.16$ & $0.512 \pm 0.06$ & $24.24 \pm 0.12$ & $1.1 \pm 0.04$ \\
\hline F8 & $24.58 \pm 0.21$ & $0.510 \pm 0.02$ & $0.610 \pm 0.03$ & $21.32 \pm 0.02$ & $0.112 \pm 0.01$ \\
\hline F9 & $25.67 \pm 0.31$ & $0.467 \pm 0.12$ & $0.455 \pm 0.11$ & $22.52 \pm 0.08$ & $1.39 \pm 0.02$ \\
\hline F10 & $30.90 \pm 0.25$ & $0.458 \pm 0.03$ & $0.581 \pm 0.07$ & $25.9 \pm 0.13$ & $0.078 \pm 0.27$ \\
\hline F11 & $28.13 \pm 0.37$ & $0.486 \pm 0.14$ & $0.614 \pm 0.02$ & $18.12 \pm 0.15$ & $0.154 \pm 0.07$ \\
\hline
\end{tabular}

All formulas represent (Number of experiments $n=3$, mean \pm SD)

\section{Carr's compressibility index}

Carr's Index is considered as a mensuration of powder bridge strength and stability. Thus, the values of compressibility index range between $17.32 \pm 0.14 \%$ to $28.78 \pm 0.03 \%$ as showed in (table 2 ) and this point outs good flowability of the powder blend and represented low cohesiveness; that is adequate for the essential tableting technological parameters [28].

\section{Hausner's ratio}

Hausner's ratio was measured to determine the inter-particulate friction and consolidation. The powder blend of most formulas has Hausner ratio below 1.25 as showed in (table 2) and thus indicate good flow properties so these values displayed that the powder blend had acceptable flow properties [29].

\section{Post-compression parameters \\ Content uniformity}

For content uniformity test, table 3 , results are in the acceptable range, indicating that all tablets fit (BP) criteria; in which each tablet drug content was between $98.4 \%$ and $99.7 \%$ of related average content [16].

\section{Tablet thickness}

The thickness of the tablets was showed in (table 3); that was between $(4.2 \pm 0.01-4.8 \pm 0.03) \mathrm{mm}$. From these results, it can be detected that those batches with a low concentration of polymer showed less thickness of the tablets obtained due to lower concentrations of polymer. Moreover, a higher concentration of polymers produces more thickness for tablets and less dense [30].

Table 3: Post-compression parameters of the prepared amlodipine floating tablets

\begin{tabular}{|c|c|c|c|c|c|c|}
\hline Formula code & Thickness (mm) & Diameter (mm) & Hardness $\left(\mathrm{Kg} / \mathrm{cm}^{2}\right)$ & Weight variation (mg) & Friability (\%) & Drug content (\%) \\
\hline F1 & $4.2 \pm 0.01$ & $8.04 \pm 0.03$ & $7.2 \pm 0.02$ & $199.2 \pm 1.63$ & $0.48 \pm 0.05$ & $99.3 \pm 0.61$ \\
\hline $\mathrm{F} 2$ & $4.2 \pm 0.02$ & $8.04 \pm 0.01$ & $7.2 \pm 0.01$ & $199.1 \pm 2.51$ & $0.51 \pm 0.12$ & $98.9 \pm 0.57$ \\
\hline F3 & $4.3 \pm 0.05$ & $8.01 \pm 0.02$ & $7.3 \pm 0.01$ & $199.5 \pm 2.82$ & $0.52 \pm 0.01$ & $99.3 \pm 0.77$ \\
\hline F4 & $4.5 \pm 0.10$ & $8.03 \pm 0.02$ & $7.3 \pm 0.03$ & $199.2 \pm 2.71$ & $0.45 \pm 0.11$ & $98.8 \pm 0.96$ \\
\hline F5 & $4.5 \pm 0.15$ & $8.02 \pm 0.01$ & $7.4 \pm 0.02$ & $198.8 \pm 1.92$ & $0.43 \pm 0.03$ & $99.7 \pm 0.45$ \\
\hline F6 & $4.4 \pm 0.02$ & $8.03 \pm 0.05$ & $7.3 \pm 0.02$ & $199.3 \pm 2.25$ & $0.52 \pm 0.07$ & $98.6 \pm 0.91$ \\
\hline F7 & $4.3 \pm 0.01$ & $8.02 \pm 0.03$ & $7.4 \pm 0.02$ & $198.9 \pm 1.15$ & $0.41 \pm 0.04$ & $99.4 \pm 0.81$ \\
\hline F8 & $4.6 \pm 0.01$ & $8.01 \pm 0.01$ & $7.4 \pm 0.03$ & $199.2 \pm 2.11$ & $0.40 \pm 0.01$ & $99.2 \pm 0.62$ \\
\hline F9 & $4.8 \pm 0.03$ & $8.01 \pm 0.01$ & $7.5 \pm 0.01$ & $199.1 \pm 2.32$ & $0.53 \pm 0.02$ & $99.3 \pm 0.73$ \\
\hline F10 & $4.5 \pm 0.02$ & $8.02 \pm 0.02$ & $7.4 \pm 0.02$ & $199.2 \pm 1.85$ & $0.43 \pm 0.14$ & $98.4 \pm 0.94$ \\
\hline F11 & $4.4 \pm 0.05$ & $8.01 \pm 0.01$ & $7.3 \pm 0.02$ & $199.2 \pm 1.91$ & $0.51 \pm 0.06$ & $98.4 \pm 0.88$ \\
\hline
\end{tabular}

All formulas represent (Number of experiments $n=3$, mean \pm SD) 


\section{Hardness test}

In table 3 the hardness of the tablets was between $(7.2 \pm 0.01-7.5 \pm 0.01)$ $\mathrm{kg} / \mathrm{cm}^{2}$ and this confirms best characteristics of handling for all the batches. The study shows a slight increase in the hardness of tablet containing the largest quantity of ethylcellulose (EC) as shown in (F9), this may be due to the increase in density of powders blend and a reasonable increase in the number of interaction points or the bonding surface area that governs the tablet more hardness which is confirmed by the increase in thickness of tablet as shown in F9 [5].

\section{Friability test}

The friability of the tablets normally performed and quite expectedly as showed in (table 3). The results of all formulas were in the range $(0.41 \pm 0.04-0.53 \pm 0.02) \%$. This fact appears to specify that the plasticity of ethylcellulose (EC) ameliorate the cohesion strength of the tablet. According to this, the recorded friability values for the specified formulas were under $1 \%$ which can generally be regarded as a desirable mechanical resistance of the tablet $[31,32]$.

\section{Weight variation}

Weight is compendial standard to assess the quality of tablets, and thus the weight variation test must indicate that all the tablets were uniform with low standard deviation values. In case of amlodipine floating tablets; (tablet 3 ) demonstrate that weight variation of all formulas was in the range of $(198.8 \pm 1.92-199.5 \pm 2.82)$. The formulated matrix tablets met the acceptable pharmacopeial range $(>0.5 \%)$ which indicate good uniformity requirement of weight [33].

\section{Floating behavior of tablets}

Floating behavior of amlodipine tablets including floating lag time and total floating time was investigated and showed in (table 4). These floating tablets were all set with different grades of hydrophilic polymers in addition to hydrophobic polymer and then evaluated for the entrapment of $\mathrm{CO}_{2}$ bubble efficiency and the ability to maintain matrix integrity.

Floating tablets prepared with hydroxypropyl methylcellulose (HPMC) E50 [hydrocolloid gelling agent] (F1-F5) absorbs water and swell upon contact with an aqueous medium $(0.1 \mathrm{~N} \mathrm{HCl}, \mathrm{pH} 1.2)$, which retarded the drug release. In addition, the floating property of these prepared tablets was evaluated to determine the effect of increasing hydroxypropyl methylcellulose (HPMC) E50 concentration. This polymer was found capable of retaining the matrix integrity for a desired time span and a decrease in floating lag time was achieved, moreover, that total floatation time was maintained for more than $24 \mathrm{~h}$. This may be assigned to the fact that as the raised in volume was greater in comparison to the increase in mass during swelling, the density decreases, and the systems started to float [34].

Ethylcellulose (EC) $5 \mathrm{mp}$. a. s. was added to the formulation (F6-F9) release retardant polymer being insoluble in gastric $\mathrm{pH}$. It was observed that floating lag time and total floatation time is elevated for these formulations by increasing concentration of ethylcellulose. This is due to ethylcellulose (EC) hydrophobic nature, so it can retard the diffusion of the dissolution medium to the matrix, and this will delay the reaction between the dissolution medium and $\mathrm{NaHCO}_{3}$ (Sodium bicarbonate); thus, the generation of $\mathrm{CO}_{2}$ will be affected, and hence floatation time will be prolonged [35].

Sodium bicarbonate stimulates carbon dioxide generation in the incidence of dissolution medium $(0.1 \mathrm{~N} \mathrm{HCl})$. The gas produced is trapped and protected within the gel, formed by hydration of polymer, thus diminishing the density of the tablet. As the density of the tablet falls below $1 \mathrm{~g} / \mathrm{ml}$, the tablet turns out buoyant [36]. The effect of sodium bicarbonate on the buoyancy of the tablets was evaluated in formulas (F9 and F10) by using it at two diverse levels $5,10 \mathrm{mg}$ per tablet. Table 4 illustrates the outcomes of the in vitro buoyancy, such that; all formulations kept their matrix integrity for more than $24 \mathrm{~h}$. The result of the total floating time for the formulations was more than $24 \mathrm{~h}$ irrespective to the amount of sodium bicarbonate $\left(\mathrm{NaHCO}_{3}\right)$ whereas floating lag time decreases with increasing amount of sodium bicarbonate [37]. The carbon dioxide generated is widely relative to the quantity of sodium bicarbonate $\left(\mathrm{NaHCO}_{3}\right)$ in the tablet. The decrease in floating lag time of the formulations can be referred to the availability of an increased amount of $\mathrm{CO}_{2}$ as the concentration of sodium bicarbonate $\left(\mathrm{NaHCO}_{3}\right)$ was increased, being captured in the formed gel to give buoyancy [38].

In Formula 11, the floating tablets that prepared with a higher viscosity grade of hydroxypropyl methylcellulose (HPMC) K100M were observed to have increased in floating lag time and total floatation time for more than $24 \mathrm{~h}$ in comparison with F10 that prepared with a lower grade of hydroxypropyl methylcellulose (HPMC). This was probably owing to more polymer entanglement and more gel strength also, to the smaller efficacious molecular diffusion area within a high viscosity as compared with a lowviscosity grade of hydroxypropyl methylcellulose (HPMC) [39].

Table 4: Floating lag time and total floating time of formulations

\begin{tabular}{|c|c|c|c|c|c|c|c|c|c|c|c|}
\hline Formulas tests & F1 & F2 & F3 & F4 & F5 & F6 & F7 & F8 & F9 & F10 & F11 \\
\hline Floating Lag Time (min) & 4 & 3 & 2.5 & 1.75 & 0.5 & 3.5 & 3.75 & 4 & 8 & 3 & 4.5 \\
\hline Total Floating Time (h) & $>24$ & $>24$ & $>24$ & $>24$ & $>24$ & $>24$ & $>24$ & $>24$ & $>24$ & $>24$ & $>24$ \\
\hline
\end{tabular}

\section{In vitro dissolution studies}

It was evident from fig. 1 that formulations (F1-F3) showed rapid release within $7 \mathrm{~h}$, while in (F4 and F5) they showed a delay in drug release for $8 \mathrm{~h}$ and $11 \mathrm{~h}$ respectively. This clearly elucidates that release rate influenced by hydroxypropyl methylcellulose (HPMC) E50 concentration significantly $(\mathrm{p}<0.05)$, as the concentration of hydroxypropyl methylcellulose (HPMC), E50 increased; the release rate decreased [40]. Accordingly, it may be imputed to the increment in the molecular weight of the polymer, resulting in an increased entanglement of the macromolecules. Thus, the mobility of the polymer concatenations decreased, minimizing the free volume accessible for diffusion. Hence, the possibility for a drug molecule to jump from one cavity to another is diminished, leading to a diminished mass transfer rate [34].

In addition, formulations (F6-F9) were used to inspect the effect of ethylcellulose (EC) $5 \mathrm{mp}$. a. s. concentration on drug release as showed in fig. 2. The results pointed out that as the concentration of $\mathrm{EC}$ raised; the drug release rate decrease significantly $(\mathrm{p}<0.05)$. This is owing to the hydrophobic polymer characteristics that are essentially insoluble in this media which retards the drug release to a greater extent [41]. A more plausible explanation for this phenomenon would be the higher molecular weight ethylcellulose (EC) $5 \mathrm{mp}$. a. s. the polymer was less soluble in water and thus with lower aqueous viscosity. Moreover, formula 8 showed an optimum drug release as there was a combination effect between hydroxypropyl methylcellulose (HPMC) E50 with hydrophilic effect and ethylcellulose (EC) $5 \mathrm{mp}$. a. s. with hydrophobic effect [42].

Formulations (F8 and F10) were chosen to determine the effect of sodium bicarbonate $\left(\mathrm{NaHCO}_{3}\right)$ concentration on drug release. The results showed that a non-significant effect $(p>0.05)$ for increasing the concentration of sodium bicarbonate on drug release rate as showed in fig. 3.

The release of amlodipine from formulations (F8 and F11) was studied to determine the effect of various hydroxypropyl methylcellulose (HPMC) grades on dissolution profile and as showed in fig. 4. The cumulative drug release rate from hydroxypropyl methylcellulose (HPMC) K100M was significantly $(\mathrm{p}<0.05)$ lesser than hydroxypropyl methylcellulose (HPMC) E50. This is owing to decreases in the primary burst release which could be due to increase swelling of the high viscosity polymer with increasing 
amount; forming greater matrix integrity and longer diffusional path length; thus, less permeability of water. As perspective, the drug release rate was relying on the viscosity grade, and concentration of the polymers utilized [43].

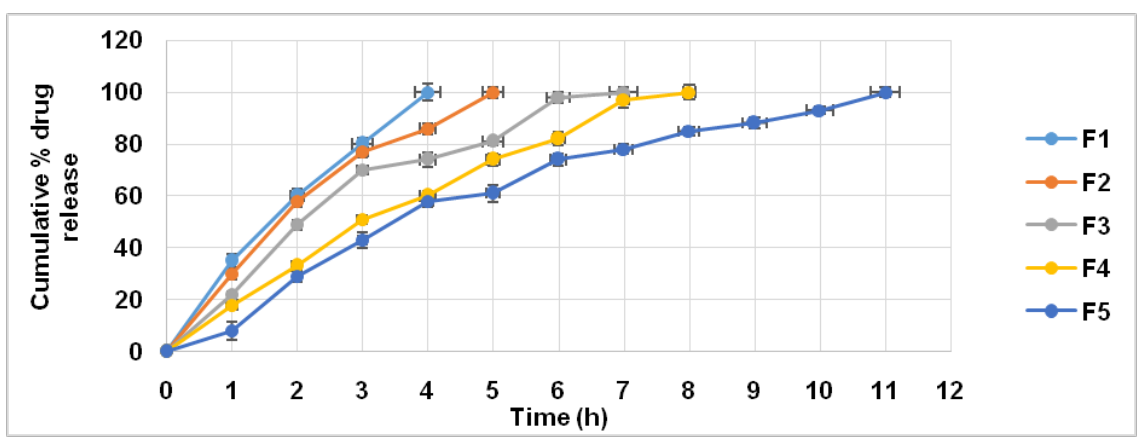

Fig. 1: Dissolution profile of amlodipine from floating tablets containing different concentrations of HPMC E50 (F1-F5), data given in mean $\pm S D, n=3$

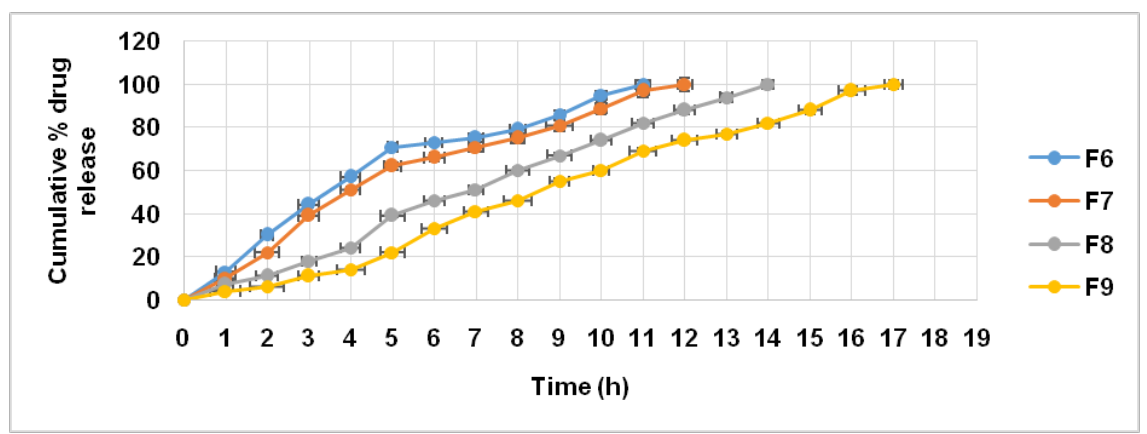

Fig. 2: Dissolution profile of amlodipine from floating tablets containing different concentrations of EC 5 mp. a. s. (F6-F9), data given in mean $\pm S D, n=3$

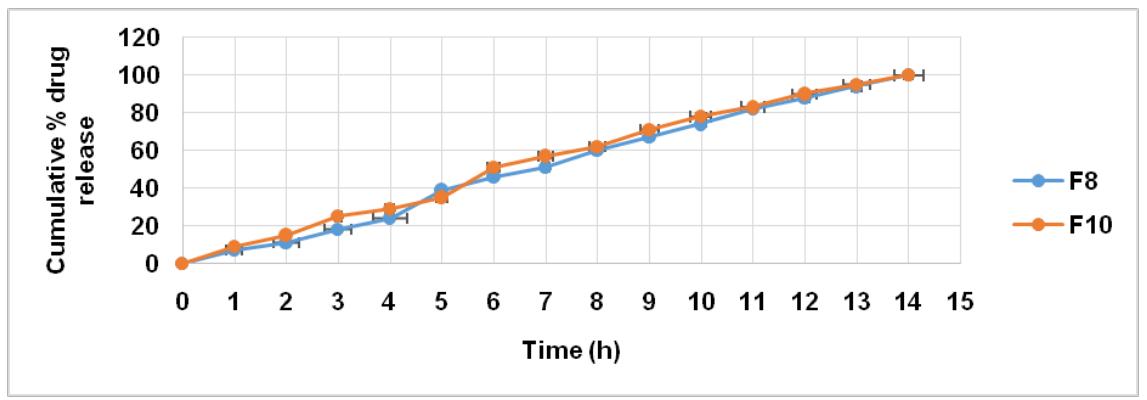

Fig. 3: Dissolution profile of amlodipine from floating tablets containing different concentrations of $\mathrm{NaHCO}_{3}$ (F8 and $\left.\mathrm{F} 10\right)$, data given in mean $\pm S D, n=3$

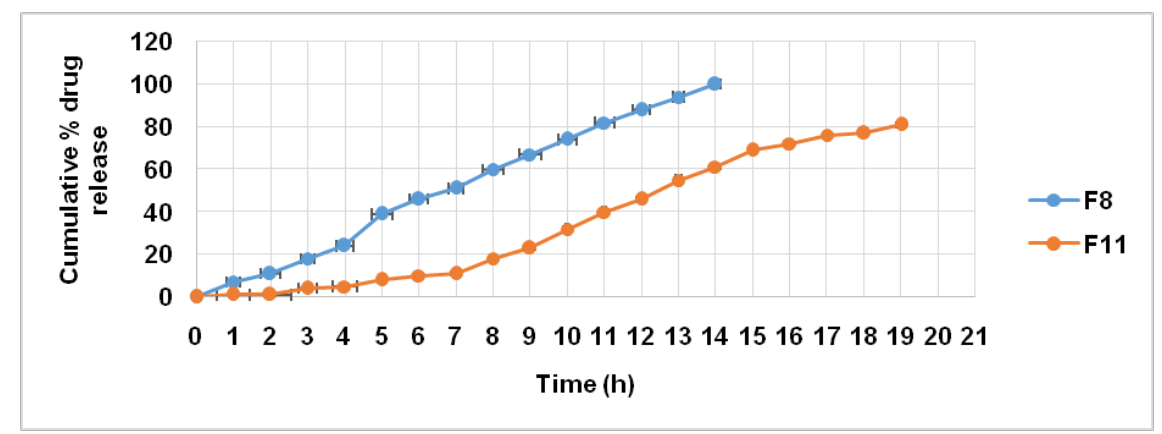

Fig. 4: Dissolution profile of amlodipine from floating tablets containing different grades of HPMC (F8 and F11), data given in mean \pm SD, $\mathbf{n}=\mathbf{3}$ 


\section{Kinetic assessment of dissolution data}

The drug release date acquired were extrapolated by zero order, first order, Higuchi, and Korsmeyer-Peppas equations to distinguish the mechanism of drug release.

The data from table 5 shows that F1-F4 have $\mathrm{n}$ value ranging from 0.45 to 0.89 that could indicate coupled diffusion and relaxation (nonFickian) release mechanism [44]. While F4 was used to study the influence of ethylcellulose (EC) concentration on drug release kinetics as it provides the longest time for drug release and higher regression $\left(\mathrm{R}^{2}\right)$ for zero order kinetic. In addition, F6-F9 were used to study the effect of ethylcellulose (EC) $5 \mathrm{mp}$. a. s. concentration on drug release kinetics. Thus, F8 was selected as an optimum formula, this is due to the $\left(\mathrm{R}^{2}\right)$ and $(\mathrm{n})$ value indicate purely relaxation zero order drug release with good delayed in drug release, and this will maximize the efficacy while minimizing dose frequency and toxicity [45].

Table 5: In vitro release kinetic data for the prepared formulations

\begin{tabular}{|c|c|c|c|c|c|c|c|c|c|}
\hline \multirow[t]{2}{*}{ Formulation } & \multicolumn{2}{|l|}{ Zero-order } & \multicolumn{2}{|c|}{ First-order } & \multicolumn{2}{|c|}{ Higuchi-order } & \multicolumn{3}{|c|}{ Korsmeyer-Peppas } \\
\hline & $K_{0}\left(m h^{-1}\right)$ & $\mathbf{R}^{2}$ & $K_{1}\left(h^{-1}\right)$ & $\mathbf{R}^{2}$ & $K_{H}\left(h^{-1 / 2}\right)$ & $\mathbf{R}^{2}$ & $\mathbf{n}$ & $K_{k p}\left(h^{-1 / 3}\right)$ & $\mathbf{R}^{2}$ \\
\hline F1 & 22.5 & 0.9959 & -0.2559 & 0.9898 & 61.416 & 0.9999 & 0.7552 & 1.5459 & 0.9994 \\
\hline $\mathrm{F} 2$ & 18.7 & 0.9509 & -0.2358 & 0.9986 & 57.054 & 0.9841 & 0.7776 & 1.4971 & 0.9784 \\
\hline F3 & 14.3 & 0.8896 & -0.1519 & 0.9662 & 47.955 & 0.9476 & 0.8180 & 1.3909 & 0.9427 \\
\hline $\mathrm{F} 4$ & 12.914 & 0.9860 & -0.1318 & 0.9841 & 45.143 & 0.9950 & 0.8589 & 1.2647 & 0.9948 \\
\hline F5 & 10.476 & 0.9481 & -0.1085 & 0.9889 & 41.696 & 0.9885 & 1.0776 & 1.0345 & 0.9375 \\
\hline F6 & 8.6167 & 0.9073 & -0.0941 & 0.9747 & 36.378 & 0.9666 & 0.8369 & 1.1955 & 0.9553 \\
\hline F7 & 8.7 & 0.9360 & -0.0832 & 0.9923 & 36.450 & 0.9821 & 0.9506 & 1.0670 & 0.9653 \\
\hline F8 & 7.709 & 0.9915 & -0.0723 & 0.9585 & 33.934 & 0.9707 & 0.9635 & 0.9208 & 0.9912 \\
\hline F9 & 6.611 & 0.9892 & -0.0574 & 0.9606 & 32.108 & 0.9577 & 1.2735 & 0.4856 & 0.9811 \\
\hline F10 & 7.8 & 0.9931 & -0.0686 & 0.9530 & 34.259 & 0.9680 & 1.0936 & 0.7780 & 0.9861 \\
\hline F11 & 5.1719 & 0.9638 & -0.0423 & 0.9181 & 28.136 & 0.8924 & 1.7381 & -0.2718 & 0.97 \\
\hline
\end{tabular}

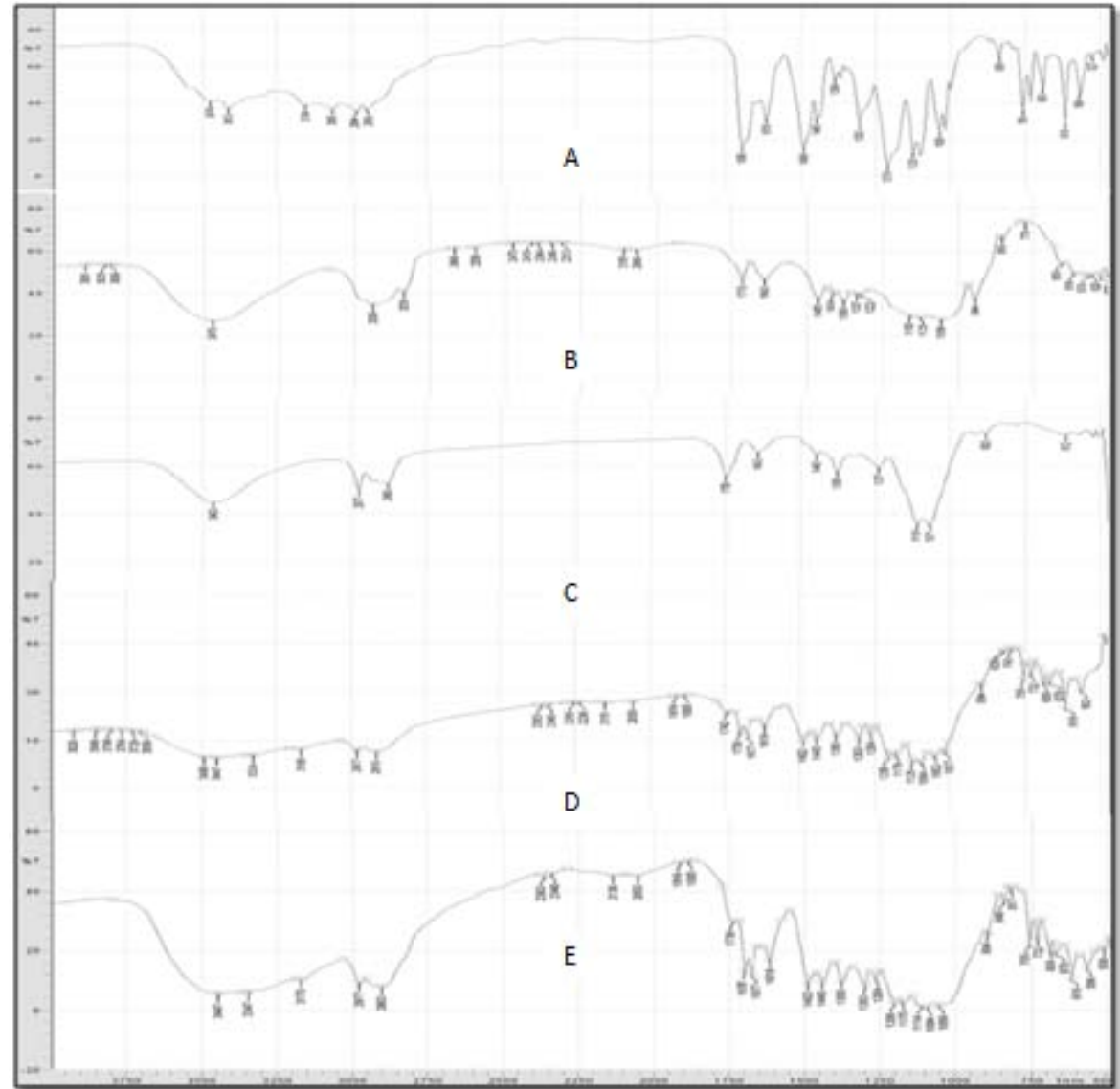

Fig. 5: The FT-IR spectra for (A) pure amlodipine; (B) HPMC E50; (C) EC 5 mp. a.s; (D) Physical mixture; (E) Amlodipine floating tablet [F8]

\section{Drug-excipients interaction study and identification}

\section{Fourier transform infrared spectroscopy (FT-IR)}

FT-IR spectroscopy was used to establish the compatibility of amlodipine besylate with polymers. The pure drug powder (fig. 5A), polymers [HPMC E50, EC $5 \mathrm{mp}$. a. s] as showed in (fig. 5B and 5C) respectively, a physical mixture of the drug with polymers (fig. 5D); in addition to amlodipine floating tablet (F8) as showed in (fig. 5E) were individually scanned.

The FT-IR spectrum for pure drug was characterized by the principal absorption bands at $3415 / \mathrm{cm}$ and $3154 / \mathrm{cm}$ due to $\mathrm{N}-\mathrm{H}$ (stretching), 3065/cm due to $=\mathrm{C}-\mathrm{H}$ (aromatic stretching), 2984 and $2950 / \mathrm{cm}$ due to $\mathrm{C}-\mathrm{H}$ (stretch ing), $1696 / \mathrm{cm}$ due to $\mathrm{C}=\mathrm{O}$ (stretching vibration), $1615 / \mathrm{cm}$ and $1488 / \mathrm{cm}$ due to $\mathrm{C}=\mathrm{C}$ (ring stretching), 
$1445 / \mathrm{cm}$ due to $\mathrm{CH}_{3}$ (stretching),1303 and $1125 / \mathrm{cm}$ due to C-N (stretching), $1210 / \mathrm{cm}$ due to C-O-C (stretching), $836 / \mathrm{cm}, 755 / \mathrm{cm}$ and $693 / \mathrm{cm}$ due to $\mathrm{C}-\mathrm{H}$ (out of plane bending of aromatic ring) [46]. The IR spectra patterns for physical mixture and amlodipine floating tablet [F8] were compared with the IR spectrum of the pure drug for confirmation of common peaks. All the spectra amlodipine besylate with polymers showed no significant variation in height, intensity and position of peaks, suggesting that drug and excipients were compatible. This indicates no interaction between pure amlodipine powder and the used polymers Subsequently, it can be decided that the drug is in a free state and can release with ease from the formulation.
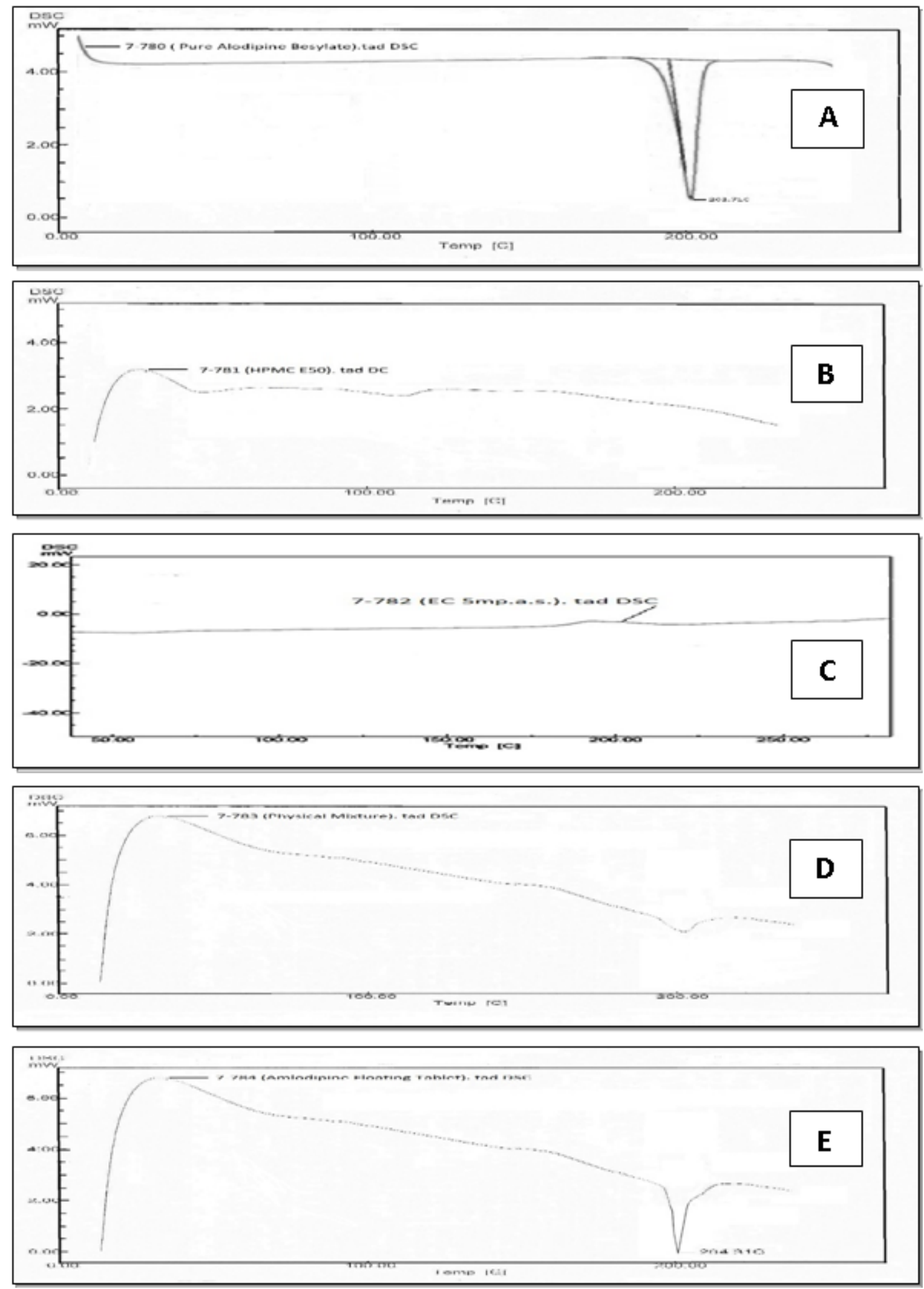

Fig. 6: Differential scanning calorimetry thermograms of (A) Pure amlodipine; (B) HPMC E50; (C) EC 5 mp. a. s.; (D) Physical mixture; (E) Amlodipine floating tablet (F8) 


\section{Differential scanning calorimetry (DSC)}

DSC thermogram of pure amlodipine besylate power showed in (fig. $6 \mathrm{~A})$ which represents a sharp endothermic peak at $202.71{ }^{\circ} \mathrm{C}$ corresponding to the drug melting point indicating its crystalline nature [47]. While the DSC thermogram of hydroxypropyl methylcellulose (HPMC) E50 showed in (fig. 6B) has broad endotherm due to residual moisture; thus, the absence of any peak beside that of residual water revealing its amorphous nature [48]. In addition, the DSC thermogram curve of ethylcellulose (EC) $5 \mathrm{mp}$. a. $\mathrm{s}$ also showed no peaks (fig. 6C), signifying the complete amorphous nature of ethyl cellulose [49]

The physical mixture in (fig. 6D) showed no shift in the melting endotherm for amlodipine besylate but giving broad endotherm indicating that there is no chemical interaction between the amlodipine besylate and mixture of polymers (HPMC E50 and EC 5 mp. a. s.); nonetheless depicted some miscibility of the drug with polymers [50]. The DSC thermogram of the optimized formula (F8) depicted the similar melting point as observed with the pure amlodipine besylate powder. DSC thermogram of optimized formulation also shows some step changes in heat curve. These step changes are glass transition temperature which indicates the amorphous nature of other components of formulation like hydroxypropyl methylcellulose (HPMC) E50, ethylcellulose (EC) 5 mp. a. s. as showed in (fig. 6E) [51]

\section{CONCLUSION}

This study established a unique optimal formula of amlodipine floating tablet (F8) that led to the possibility of preparing successful tablets containing a combination of hydrophilic and lipophilic polymers. A suggesting zero order mechanism for drug dissolution profile was approved via combining both hydroxypropyl methylcellulose (HPMC) E50 and ethylcellulose (EC) $5 \mathrm{mp}$. a. s. and as increasing the concentration of both as the release rate was noticed to be decreased which is the most challenging aspect of the floating drug delivery system. Also, the effect for sodium bicarbonate $\left(\mathrm{NaHCO}_{3}\right)$ on the drug release rate was non-significant. In addition, the cumulative drug release rate from high viscosity grade hydroxypropyl methylcellulose (HPMC K100M) was significantly lesser as compared with the low viscosity grade hydroxypropyl methylcellulose (HPMC E50). Thus, it can be concluded that a combination of hydroxypropyl methylcellulose (HPMC) E50 and ethylcellulose (EC) $5 \mathrm{mp}$. a. s. in the formulation was considered a promising approach for preparing efficient amlodipine floating tablet that has an ultimate solubility in acidic $\mathrm{pH}$.

\section{ACKNOWLEDGMENT}

The authors would like to thank Mustansiriyah University (www. uomustansiriyah. edu. iq) Baghdad-Iraq for its support in the present work. Also, the authors would like to give great thanks and appreciation for Dr. Masar Basim Mohsin Mohamed in the department of pharmaceutics, college of pharmacy, Mustansiriyah University, Baghdad-Iraq, for her help and generosity.

\section{AUTHORS CONTRIBUTIONS}

All authors have contributed equally

\section{CONFLICT OF INTERESTS}

No conflict of interests between authors

\section{REFERENCES}

1. Jamode P, Saigal N, Gaikwad S, Deshmane S, Swain K. Review article on bilayer sustained release tablet. World J Pharm Pharm Sci 2016;5:1550-63.

2. Mandal UK, Chatterjee B, Senjoti FG. Gastro-retentive drug delivery systems and there in vivo success: a recent update. Asian J Pharm Sci 2016;11:575-84.

3. Gupta P, Gnanarajan G, Kothiyal P. Floating drug delivery system: a review. Int J Pharm Res Rev 2015;4:37-44.
4. Saritha D, Sathish D, Rao YM. Formulation and evaluation of gastroretentive floating tablets of domperidone maleate. J Appl Pharm Sci 2012;2:68-73.

5. kumari SDC, Vengatesh S, Elango K, Damayanthi RD, Deattu N, Christina P. Formulation and evaluation of floating tablets of ondansetron hydrochloride. Int J Drug Dev Res 2012;4:265-74.

6. Uddin M, Rathi PB, Siddiqui AR, Sonawane AR, Gadade DD. Recent development in floating delivery systems for gastric retention of drugs: an overview. Asian J Bio-Pharm Sci 2011;1:26-42.

7. Nikam MS, Kale RH, Deshmane SV, Biyanik R. Preparation and evaluation of gastroretentive floating tablet containing enalapril maleate. Int J Curr Pharm Res 2014;6:45-7.

8. Ahmed A, Goyal NK, Sharma PK. Effervescent floating drug delivery system: a review. Global J Pharmacol 2014;8:478-85.

9. Narang N. An updated review on floating drug delivery system (FDDS). Int J Appl Pharm 2011;3:1-7.

10. Shilpa C, Manish B, Ajinath S. Formulation and evaluation of bilayer floating tablet of carvedilol phosphate. J Drug Delivery Ther 2012;2:9-19.

11. Gahandule M, Gadhave MV. A new venture in drug delivery: bilayer floating tablet of loop diuretics with potassium supplement: a review. Int J Pharm Pharm Res 2016;8:175-91.

12. Sheraz MA, Ahsan SF, Khan MF, Ahmed S, Ahmad I. Formulations of amlodipine: a review. J Pharm 2016:1-11. http://dx.doi.org/10.1155/2016/8961621

13. Vivek D, Vandana A. Formulation and evaluation of effervescent floating tablet of amlodipine besylate with natural polymer chitosan. J Pharm Sci Innov 2012;1:13-8.

14. Vennam S, Bhukya B. Formulation and evaluation of gastroretentive drug delivery system of amlodipine besylate floating tablets. J Drug Delivery Res 2014;3:11-21.

15. Pawar HA, Dhavale R. Development and evaluation of gastroretentive floating tablets of an antidepressant drug by thermoplastic granulation technique. Beni-Suef University J Basic Appl Sci 2014;3:122-32.

16. Rahim SA, Carter PA, Elkordy AA. Design and evaluation of effervescent floating tablets based on hydroxyethyl cellulose and sodium alginate using pentoxifylline as a model drug. Drug Des Dev Ther 2015;9:1843-57.

17. Anepu S, Duppala L, Sundari S. Formulation development, characterization, and in vitro evaluation of floating matrix dosage form of tramadol hydrochloride using various polymers. Asian J Pharm Clin Res 2017;10:281-90.

18. Damodharan N, Manimaran V, Sravanthi B. Formulation development and evaluation of delayed release doxycycline. Int J Pharm Pharm Sci 2010;2:116-9.

19. Shahi SR, Shinde SB, Zadbuke NS, Padalkar AN. Formulation development and evaluation of floating matrix tablet of verapamil HCl. Asian J Pharm 2013;7:27-35.

20. Prajapati ST, Patel LD, Patel DM. Studies on formulation and in vitro evaluation of floating matrix tablets of domperidone. Indian J Pharm Sci 2009;71:19-23.

21. Sungthongjeen S, Sriamornsak P, Puttipipatkhachorn S. Design of floating HPMC matrix tablets: effect of formulation variables on floating properties and drug release. Adv Mat Res 2011;311313:1140-3

22. Golla U, Nalla BK, Talla R, Gajam PK, Voore SK. Formulation and in vitro evaluation of gastroretentive drug delivery system of ciprofloxacin hydrochloride. Der Pharm Sinica 2011;2:33-9.

23. Pawar HA, Gharat PR, Dhavale RV, Joshi PR, Rakshit PP. Development and evaluation of gastroretentive floating tablets of an antihypertensive drug using hydrogenated cottonseed oil. ISRN Pharm 2013:1-9. Doi:10.1155/2013/137238

24. Chowdhury MEH, Pathan MSI. Preparation and evaluation of floating matrix tablets of ranitidine hydrochloride. Pharma Innovation 2012;1:43-50.

25. Arza RAK, Gonugunta CSR, Veeraredd PR. Formulation and evaluation of swellable and floating gastroretentive ciprofloxacin hydrochloride tablets. AAPS PharmSciTech 2009;10:220-6.

26. Kadivar A, Kamalidehghan B, Javar HA, Davoudi ET, Zaharuddin ND, Sabeti B, et al. Formulation and in vitro, in vivo evaluation 
of effervescent floating sustained-release imatinib mesylate tablet. PLOS One 2015;10:1-23

27. Hascicek C, Yuksel Tilkan G, Turkmen B, Ozdemir N. Effect of formulation parameters on the drug release and floating properties of gastric floating two-layer tablets with acetylsalicylic acid. Acta Pharm 2011;61:303-12.

28. Pati N, Gupta V, Velivela S, Mayasa V. Comparative study of effect various types of polymers on the extended release of tapentadol HCl. Int J Pharm Tech 2016;8:12762-75.

29. Jagdale S, Agavekar A, Pandya S, Kuchekar B, Chabukswar A. Formulation and evaluation of gastroretentive drug delivery system of propranolol hydrochloride. AAPS PharmSciTech 2009;10:1071-9.

30. Kesarla RS, Vora PA, Sridhar BK, Patel G, Omri A. Formulation and evaluation of floating tablet of the H2-receptor antagonist. Drug Devel Ind Pharm 2014;41:1-13.

31. El-Bagory I, Barakat N, Ibrahim MA, El-Enazi F. Formulation and in vitro evaluation of theophylline matrix tablets prepared by direct compression: effect of polymer blends. Saudi Pharm J 2012;20:229-38.

32. Cifuentes C, Aguilar-De-Leyva A, Rajabi-Siahboomir A, Caraballo I. Critical points in ethylcellulose matrices: Influence of the polymer, drug and filler properties. Acta Pharm 2013:63:115-29.

33. Ashok KP, Damodar KS. Effect of hydrophilic and hydrophobic polymers and fillers on controlled release matrix tablets of acyclovir. Der Pharm Sinica 2013;4:143-50.

34. Biswas M, Gupta RN, Parhi R, Sethi KK, Sahoo SK Formulation and in vitro evaluation of gastroretentive floating drug delivery system of ritonavir. Turkish J Pharm Sci 2013;10:69-86.

35. Toma NM, Khalil YI. Formulation and evaluation of bilayer tablets containing immediate release aspirin layer and floating clopidogrel layer. Iraqi J Pharm Sci 2013;22:40-9.

36. Gharti KP, Thapa P, Budhathoki U, Bhargava A. Formulation and in vitro evaluation of hydroxypropyl methylcellulose and polyethylene oxide using ranitidine $\mathrm{HCl}$ as a model drug. J Young Pharm 2012;4:201-8.

37. Vanitha K, Varma M, Ramesh A. Floating tablets of hydralazine hydrochloride: optimization and evaluation. Braz J Pharm Sci 2013;49:811-9.

38. Meka L, Kesavan B, Chinnala KM, Vobalaboina V, Yamsani MR. Preparation of a matrix type multiple-unit gastro-retentive floating drug delivery system for captopril based on gas formation technique: in vitro evaluation. AAPS PharmSciTech 2008;9:612-9.
39. Patel DM, Patel NM, Pandya NN, Jogani PD. Formulation and optimization of carbamazepine floating tablets. Indian J Pharm Sci 2007;69:763-7.

40. Sucharitha M, Devi AN, Priya VP, Shyamala, Sharma JVC Formulation and evaluation of gastroretentive floating tablets of valsartan. World J Pharm Pharm Sci 2013;3:689-702.

41. Ammar HO, Makram TS, Mosallam S. Effect of polymers on the physicochemical properties and biological performance of fenoprofen calcium dihydrate-triacetyl-cyclodextrin complex. Pharmaceutics 2017;9:1-19.

42. Katikaneni PR, Upadrashta SM, Neau SH, Mitra AK Ethylcellulose matrix controlled-release tablets of a watersoluble drug. Int J Pharm 1995; 123:119-25.

43. El Nabarawi MA, Teaima MH, Abd El-Monem RA, Nabarawy NA, Gaber DA. Formulation, release characteristics, and bioavailability study of gastroretentive floating matrix tablet and floating raft system of mebeverine $\mathrm{HCl}$. Drug Des Devel Ther 2017;11:1081-93.

44. Efentakis M, Peponaki C. Formulation study and evaluation of matrix and three-layer tablet sustained drug delivery systems based on carbopols with isosorbite mononitrate. AAPS PharmSciTech 2008;9:917-23.

45. Yadav G, Bansal M, Thakur N, Khare S, Khare P. Multilayer tablets and their drug release kinetic models for the oral controlled drug delivery system. Middle-East J Sci Res 2013;16:782-95.

46. Janakidevi S. Formulation, evaluation and optimization of amlodipine besylate melt in mouth tablets prepared by direct compression method using natural and synthetic super disintegrating agents. Int J Pharm Bio Sci 2014;5:244-57.

47. Manimaran V, Damodharan N. Development of fast-dissolving tablets of amlodipine besylate by solid dispersion technology using poloxamer 407 and poloxamer 188. Asian J Pharm Clin Res 2017;10:135-41.

48. Vora C, Patadia R, Mittal K, Mashru R. Preparation and characterization of dipyridamole solid dispersions for stabilization of supersaturation: effect of precipitation inhibitors type and molecular weight. Pharm Dev Technol 2015;21:847-55.

49. Govindasamy G, Krishnamoorthy K, Rajappan M. Selection of excipients for nanoparticles formulations of nateglinide through drug-excipients compatibility study. Int J Pharm Pharm Sci 2013;5:371-7.

50. Desai J, Alexander K, Riga A. Characterization of polymeric dispersions of dimenhydrinate in ethyl cellulose for controlled release. Int J Pharm 2006;308:115-23.

51. Choudhari PK, Jain HK, Sharma P, Srivastava B. A novel co-processed directly compressible release-retarding polymer: in vitro, solid state and in vivo evaluation. Future J Pharm Sci 2018;4:29-40. 